ARTICLE

\title{
Hierarchy of bond stiffnesses within icosahedral-based gold clusters protected by thiolates
}

Seiji Yamazoe ${ }^{1,2}$, Shinjiro Takano ${ }^{1}$, Wataru Kurashige ${ }^{3}$, Toshihiko Yokoyama ${ }^{4}$, Kiyofumi Nitta ${ }^{5}$, Yuichi Negishi ${ }^{3}$ \& Tatsuya Tsukuda1,2

Unique thermal properties of metal clusters are believed to originate from the hierarchy of the bonding. However, an atomic-level understanding of how the bond stiffnesses are affected by the atomic packing of a metal cluster and the interfacial structure with the surrounding environment has not been attained to date. Here we elucidate the hierarchy in the bond stiffness in thiolate-protected, icosahedral-based gold clusters $\mathrm{Au}_{25}\left(\mathrm{SC}_{2} \mathrm{H}_{4} \mathrm{Ph}\right)_{18}$, $\mathrm{Au}_{38}\left(\mathrm{SC}_{2} \mathrm{H}_{4} \mathrm{Ph}\right)_{24}$ and $\mathrm{Au}_{144}\left(\mathrm{SC}_{2} \mathrm{H}_{4} \mathrm{Ph}\right)_{60}$ by analysing $\mathrm{Au} \mathrm{L}_{3}$-edge extended $\mathrm{X}$-ray absorption fine structure data. The $\mathrm{Au}-\mathrm{Au}$ bonds have different stiffnesses depending on their lengths. The long Au-Au bonds, which are more flexible than those in the bulk metal, are located at the icosahedral-based gold core surface. The short Au-Au bonds, which are stiffer than those in the bulk metal, are mainly distributed along the radial direction and form a cyclic structural backbone with the rigid Au-SR oligomers.

\footnotetext{
${ }^{1}$ Department of Chemistry, School of Science, The University of Tokyo, 7-3-1 Hongo, Bunkyo-ku, Tokyo 113-0033, Japan. ${ }^{2}$ Elements Strategy Initiative for Catalysts and Batteries (ESICB), Kyoto University, Katsura, Kyoto 615-8520, Japan. ${ }^{3}$ Department of Applied Chemistry, Faculty of Science, Tokyo University of Science, 1-3 Kagurazaka, Shinjuku-ku, Tokyo 162-8601, Japan. ${ }^{4}$ Department of Materials Molecular Science, Institute for Molecular Science, Myodaiji, Okazaki, Aichi 444-8585, Japan. 5 Japan Synchrotron Radiation Research Institute, SPring-8, 1-1-1 Koto, Sayo, Hyogo 679-5198, Japan. Correspondence and requests for materials should be addressed to T.T. (email: tsukuda@chem.s.u-tokyo.ac.jp).
} 
$\mathrm{M}$ etal nanoparticles (NPs) exhibit specific thermal properties and phase transition behaviour that are quite different from the corresponding bulk metal ${ }^{1-4}$. For example, the melting point of a metal NP is significantly depressed with respect to that of the bulk metal ${ }^{5}$. The melting of a metal NP starts with premelting of the surface layer, which then expands towards the inner core and leads to a complete transition to the liquid ${ }^{6}$. These size-specific thermal behaviours are explained in terms of the large surface energy of a metal NP. In other words, a crucial factor that governs thermal behaviours is the hierarchy of the bonding within NPs; metal-metal bonds on the surface are generally softer than those within the core $e^{3,7,8}$. The thermal behaviours of metal NPs are not only affected by their size, but also by the atomic packing of the core ${ }^{3,7-16}$ and the interaction with the environment, such as an organic ligand ${ }^{17}$ or solid support ${ }^{3,18,19}$. For example, the vibrational spectrum of a metal NP with an icosahedral (Ih) structure has a component with a vibrational frequency that is higher than those of other structures such as cuboctahedra and decahedra, which suggests the formation of stiff bonds within the $\mathrm{NPs}^{7}$. The influence of surface adsorbates on the thermal properties of metal NPs has been ascribed to a change in the bond stiffness; Pt-Pt bonds of small Pt NPs are softened by hydrogen adsorption, but stiffened by oxidation ${ }^{19}$ or capping with a polymer ${ }^{17}$. However, an atomiclevel understanding of how the bond stiffnesses are affected by a variety of structural parameters has not been attained to date because of the experimental difficulties in defining the atomic packing of a metal NP and the interfacial structure with the surrounding environment.

Recently, a series of thiolate (RS)-protected gold clusters $\mathrm{Au}_{n}(\mathrm{SR})_{m}$ with well-defined compositions have gained attention as ideal platforms to study the structure-property correlation and the size-dependent evolution of properties ${ }^{20}$. Among others, $\mathrm{Au}_{n}(\mathrm{SR})_{m}$ with $(n, m)=(25,18),(38,24)$ and $(144,60)$ have been studied most extensively as prototypical systems. Single-crystal X-ray diffraction (XRD) analysis revealed that $\mathrm{Au}_{25}(\mathrm{SR})_{18}$ and $\mathrm{Au}_{38}(\mathrm{SR})_{24}$ have icosahedral $\mathrm{Au}_{13}$ and bi-icosahedral $\mathrm{Au}_{23}$ cores, respectively, which are protected by combinations of -SR- $(\mathrm{Au}-\mathrm{SR})_{2}-$ and -SR-Au-SR- oligomers (Fig. 1) ${ }^{21-23}$. The atomic structure of $\mathrm{Au}_{144}(\mathrm{SR})_{60}$ has not yet been determined by $\mathrm{X}$-ray crystallography, but has been theoretically predicted as composed of a hollow icosahedral $\mathrm{Au}_{114}$ core protected by 30 -SR-Au-SR- oligomers (Fig. 1) ${ }^{24,25}$. In addition, it has been identified that there are distinct $\mathrm{Au}-\mathrm{Au}$ bonds with different lengths in the range of 2.7-3.3 $\AA$ in these clusters (Supplementary Fig. 1). The $\mathrm{Au}_{n}(\mathrm{SR})_{m}$ clusters $(n=25,38,144)$ provide an ideal opportunity to study the hierarchy of the bond stiffness within $\mathrm{Au}$ clusters with well-defined atomic structures and surface modification.

In this study, the stiffnesses of the $\mathrm{Au}-\mathrm{Au}$ and $\mathrm{Au}-\mathrm{S}$ bonds in $\mathrm{Au}_{n}(\mathrm{PET})_{m}$ (phenylethanethiolate $(\mathrm{PET})=\mathrm{PhC}_{2} \mathrm{H}_{4} \mathrm{~S}$ ) are examined using $\mathrm{Au} \mathrm{L}_{3}$-edge extended X-ray absorption fine structure (EXAFS) analysis, which is a powerful tool to study the local structure of the ligand-protected gold clusters ${ }^{26,27}$. The temperature dependence of the Debye-Waller (DW) factors of individual bonds are analysed in the framework of the Einstein model, in which a metal cluster is treated as an ensemble of quantum harmonic oscillators with individual Einstein temperatures that depend on the bonding. The hierarchy in the bond stiffness is elucidated. The $\mathrm{Au}-\mathrm{S}$ bonds are much stiffer than $\mathrm{Au}-\mathrm{Au}$ bonds in all the clusters and there are two types of $\mathrm{Au}-\mathrm{Au}$ bonds; one is stiffer and the other is softer than those in the bulk Au. A major portion of the shorter and stiffer $\mathrm{Au}-\mathrm{Au}$ bonds is distributed within the Ih-based Au core as radial bonds. The stiff $\mathrm{Au}-\mathrm{Au}$ bonds distributed on the surface of the core are connected by the rigid $\mathrm{Au}-\mathrm{S}$ oligomers to form a ring structure in
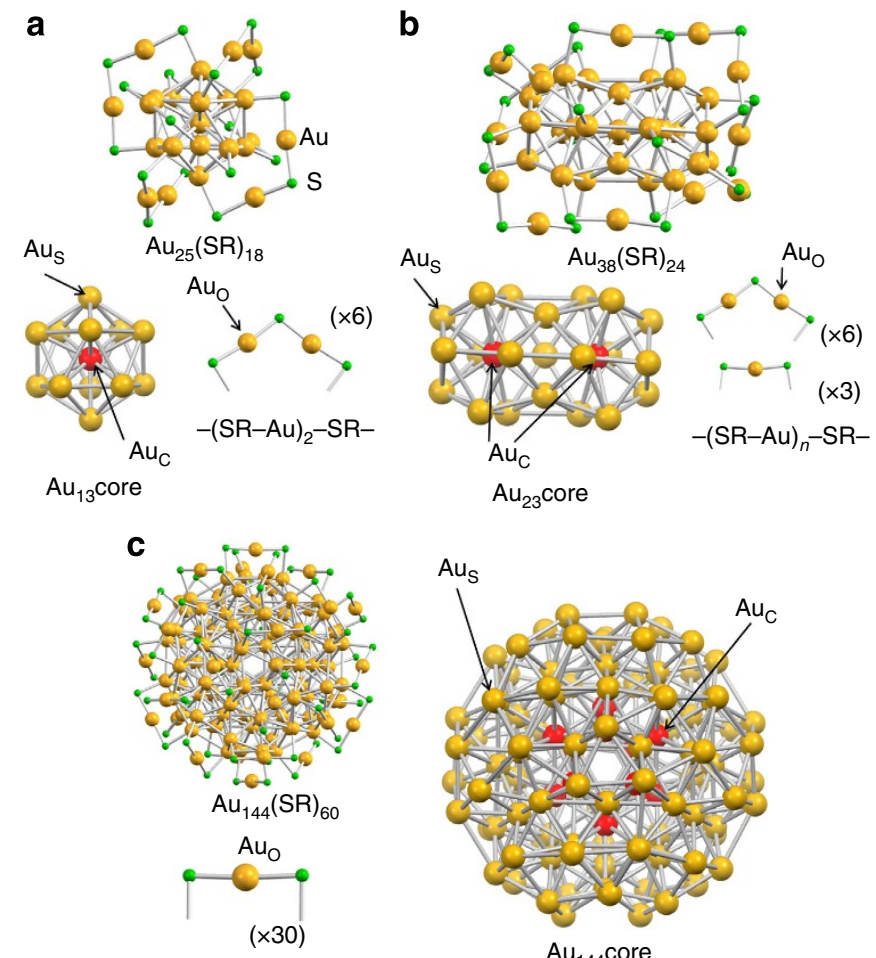

$-\mathrm{SR}-\mathrm{Au}-\mathrm{SR}-$

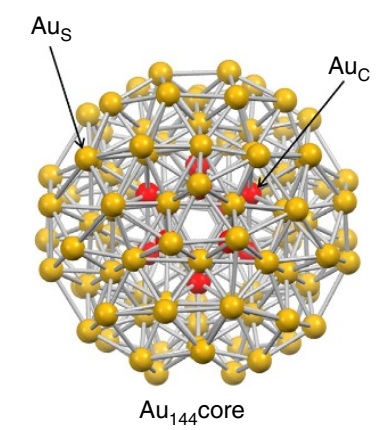

Figure 1 | Geometric structures of $\mathbf{A u}_{n}(\mathbf{S R})_{m}$ samples. (a) $\mathrm{Au}-\mathrm{S}$ framework of $A_{u_{25}}(S R)_{18}$ determined by single crystallography ${ }^{22}$, (b) Au-S framework of $\mathrm{Au}_{38}(\mathrm{SR})_{24}$ determined by single crystallography ${ }^{23}$ and (c) Au-S framework of $\mathrm{Au}_{144}(\mathrm{SR})_{60}$ predicted by density functional theory calculation (ref. 24). $A u_{C}, A_{s}$ and $A u_{O}$ represent $A u$ atoms bonded only to $\mathrm{Au}$ atoms, those bonded both to $\mathrm{Au}$ and $\mathrm{S}$ atoms, and those bridged by two $S$ atoms, respectively for $\mathrm{Au}_{25}(\mathrm{SR})_{18}$ and $\mathrm{Au}_{38}(\mathrm{SR})_{24}$. The definition of $A u C, A u_{S}$, and $A u_{0}$ for $A u_{144}(S R)_{60}$ is given in the text. $R$ is omitted for simplicity.

all the clusters. These ring structures may act as a rigid framework to enhance the thermal stability of the thiolate-protected Au clusters.

\section{Results}

Structural analysis. Figure 2a shows EXAFS oscillations of $\mathrm{Au}_{25}(\mathrm{PET})_{18}$ measured at 300 and $8 \mathrm{~K}$, respectively. EXAFS oscillation is clearly observed up to the $k$ range of $21 \AA^{-1}$ at $8 \mathrm{~K}$, whereas it is damped in the $k$ range of $>14 \AA^{-1}$ at $300 \mathrm{~K}$. Given that the EXAFS oscillation in the high $k$ region mainly originates from heavy atoms, the large amplitude in Fig. 2a suggests that thermal fluctuation of the $\mathrm{Au}-\mathrm{Au}$ bonds in $\mathrm{Au}_{25}(\mathrm{PET})_{18}$ is significantly suppressed at $8 \mathrm{~K}$. Figure $2 \mathrm{~b}$ represents Fourier transformed (FT)-EXAFS spectra of $\mathrm{Au}_{25}(\mathrm{PET})_{18}$ at 300 and $8 \mathrm{~K}$, respectively. Most notably, the peak due to $\mathrm{Au}-\mathrm{Au}$ bonds is clearly observed in the bond length $(r)$ range of $2.1-3.0 \AA$ at $8 \mathrm{~K}$, in addition to that for $\mathrm{Au}-\mathrm{S}$ bonds in the $r$ range of $1.5-2.0 \AA$, whereas the $\mathrm{Au}-\mathrm{Au}$ peak is hardly discernible at $300 \mathrm{~K}$ (Fig. 2b). Similar temperature dependence has been reported in the literature $^{26}$ and is attributed to suppression of the thermal fluctuation of $\mathrm{Au}-\mathrm{Au}$ bonds at low temperature. Previous single crystallographic study revealed that the $\mathrm{Au}-\mathrm{Au}$ bonds of $\mathrm{Au}_{25}(\mathrm{PET})_{18}$ are classified into three groups according to their lengths: the $\mathrm{Au}-\mathrm{Au}(x)$ bonds $(x=1-3)$ assigned mainly to the $\mathrm{Au}_{\mathrm{C}}-\mathrm{Au}_{\mathrm{S}}, \mathrm{Au}_{\mathrm{S}}-\mathrm{Au}_{\mathrm{S}}$ and $\mathrm{Au}_{\mathrm{S}}-\mathrm{Au}_{\mathrm{O}}$ bonds, respectively (see Fig. 1 and Supplementary Note 1; Supplementary Fig. 1a). The average coordination number $(\mathrm{CN})$ and $r$ values calculated for the 
$\mathrm{Au}-\mathrm{Au}(x)$ bonds $(x=1-3)$ are summarized in Table 1 . Based on this information, curve-fitting analysis of the FT-EXAFS data for $\mathrm{Au}_{25}(\mathrm{PET})_{18}$ at $8 \mathrm{~K}$ was conducted by assuming a single $\mathrm{Au}-\mathrm{S}$ and three types of $\mathrm{Au}-\mathrm{Au}$ bonds with different $r$ values. However, we found that contribution from the longest $\mathrm{Au}-\mathrm{Au}$ bonds is significantly smaller than the other two Au bonds due to larger DW factor (see Supplementary Discussion, Supplementary Fig. 2, and Supplementary Table 1). Thus, the FT-EXAFS data was analysed by assuming a single $\mathrm{Au}-\mathrm{S}$ and two types of $\mathrm{Au}-\mathrm{Au}$ bonds, $\mathrm{Au}-\mathrm{Au}(\mathrm{S})$ and $\mathrm{Au}-\mathrm{Au}(\mathrm{L})$. Their $\mathrm{CN}$ and $r$ values thus obtained are summarized in Table 1 . The $\mathrm{CN}$ and $r$ values for the $\mathrm{Au}-\mathrm{S}, \mathrm{Au}-\mathrm{Au}(\mathrm{S})$ and $\mathrm{Au}-\mathrm{Au}(\mathrm{L})$ bonds obtained
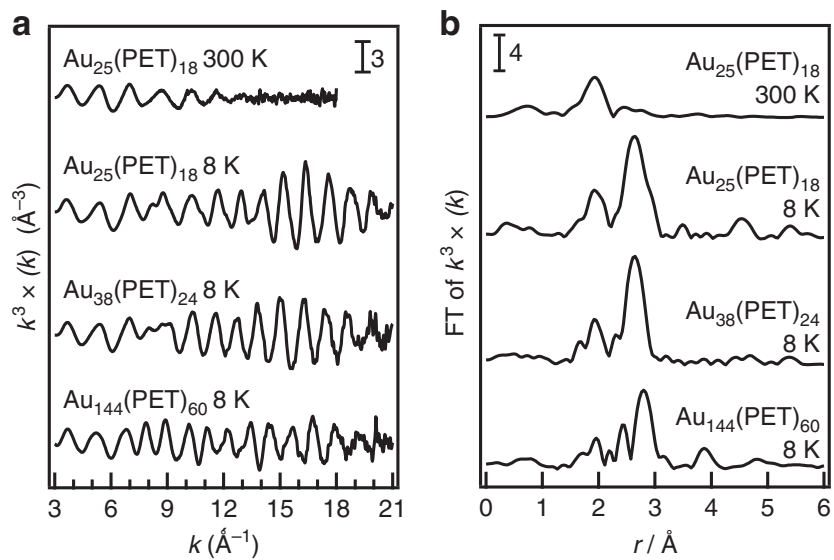

Figure 2 | EXAFS oscillations and FT-EXAFS spectra. (a) EXAFS oscillations for $\mathrm{Au}_{25}(\mathrm{PET})_{18}$ measured at 300 and $8 \mathrm{~K}, \mathrm{Au}_{38}(\mathrm{PET})_{24}$ at $8 \mathrm{~K}$, and $\mathrm{Au}_{144}(\mathrm{PET})_{60}$ at $8 \mathrm{~K}$ and (b) the corresponding FT-EXAFS spectra. by EXAFS are in good agreement with those of the Au-S, $\mathrm{Au}-\mathrm{Au}(1)$ and $\mathrm{Au}-\mathrm{Au}(2)$ bonds determined by single crystal XRD data, respectively. This agreement indicates that lowtemperature EXAFS measurements allow quantitative probing of $\mathrm{Au}-\mathrm{Au}$ bonds within the $\mathrm{Au}_{13}$ core: $\mathrm{Au}_{\mathrm{C}}-\mathrm{Au}_{\mathrm{S}}$ and $\mathrm{Au}_{\mathrm{S}}-\mathrm{Au}_{\mathrm{S}}$ bonds. The FT-EXAFS spectrum simulated assuming DW factors of $0.0027,0.0040$ and $0.0037 \AA^{2}$ (Supplementary Fig. 3) for $\mathrm{Au}_{\mathrm{C}}, \mathrm{Au}_{\mathrm{S}}$ and $\mathrm{Au}_{\mathrm{O}}$, respectively, corresponded well with the experimental spectrum (Supplementary Fig. 4).

Similar temperature dependence was observed in the $\mathrm{Au}$ $\mathrm{L}_{3}$-edge EXAFS spectrum for $\mathrm{Au}_{38}(\mathrm{PET})_{24}$ measured at $8 \mathrm{~K}$ (Fig. 2a), where a clear oscillation was observed in the $k$ range of 3.0-21.0 $\AA^{-1}$. The FT-EXAFS spectrum (Fig. $2 \mathrm{~b}$ ) at $8 \mathrm{~K}$ has peaks for the Au-S (1.5-2.0 $\AA$ ) and $\mathrm{Au}-\mathrm{Au}(2.1-3.0 \AA)$ bonds. Singlecrystal XRD measurements of $\mathrm{Au}_{38}(\mathrm{PET})_{24}$ show that $38 \mathrm{Au}$ atoms are categorized into three different sites, $\mathrm{Au}_{\mathrm{C}}, \mathrm{Au}_{\mathrm{S}}$ and $\mathrm{Au}_{\mathrm{O}}$, as in the case of $\mathrm{Au}_{25}(\mathrm{PET})_{18}$ (Fig. 1b). The length distribution of $\mathrm{Au}-\mathrm{Au}$ bonds obtained from the single crystal structure $^{23}$ is shown in Supplementary Fig. 1b. The Au-Au bonds were classified into three groups with border distances of 2.90 and $3.05 \AA$ : $\mathrm{Au}-\mathrm{Au}(x)$ bonds $(x=1-3)$ although there is larger ambiguity in the determination of the border distances than in the case of $\mathrm{Au}_{25}(\mathrm{PET})_{18}$ (Supplementary Fig. 1a). The $\mathrm{Au}-\mathrm{Au}(x)$ bonds $(x=1-3)$ are composed of mainly $A u_{C}-\mathrm{Au}_{\mathrm{S}}, \mathrm{Au}_{\mathrm{S}}-\mathrm{Au}_{\mathrm{S}}$ and $\mathrm{Au}_{\mathrm{S}}-\mathrm{Au}_{\mathrm{O}}$ bonds, respectively. The average $\mathrm{CN}$ and $r$ values calculated for the $\mathrm{Au}-\mathrm{Au}(x)$ bonds $(x=1-3)$ are summarized in Table 1. The FT-EXAFS spectrum was analysed by assuming a single $\mathrm{Au}-\mathrm{S}$ and two types of $\mathrm{Au}-\mathrm{Au}$ bonds with different lengths, $\mathrm{Au}-\mathrm{Au}(\mathrm{S})$ and $\mathrm{Au}-\mathrm{Au}(\mathrm{L})$, as in the case of $\mathrm{Au}_{25}(\mathrm{PET})_{18}$. The $\mathrm{CN}$ and $r$ values for the $\mathrm{Au}-\mathrm{S}, \mathrm{Au}-\mathrm{Au}(\mathrm{S})$ and $\mathrm{Au}-\mathrm{Au}(\mathrm{L})$ bonds obtained by curve-fitting analysis (Table 1) quantitatively agree with those for the $\mathrm{Au}-\mathrm{S}, \mathrm{Au}-\mathrm{Au}(1)$ and

\begin{tabular}{|c|c|c|c|c|c|c|c|c|}
\hline$n, m$ & Method & Bonds & $\mathrm{CN}^{\star}$ & $r(\AA)^{\dagger}$ & $\sigma^{2}\left(\AA^{2}\right)^{\ddagger}$ & R (\%) $)^{\S}$ & $\sigma_{S}^{2}\left(\AA^{2}\right)^{\|}$ & $\theta_{E}(K)^{\top}$ \\
\hline \multirow[t]{7}{*}{25,18} & EXAFS at $8 \mathrm{~K}$ & Au-S & $1.6(2)$ & $2.319(4)$ & $0.0037(18)$ & 10.6 & $0.0017(3)$ & $429(38)$ \\
\hline & & $A u-A u(S)$ & $1.5(4)$ & $2.770(3)$ & $0.0027(11)$ & & $0.0008(6)$ & $137(10)$ \\
\hline & & Au-Au (L) & $1.5(6)$ & $2.936(6)$ & $0.0040(24)$ & & $0.0020(6)$ & $101(4)$ \\
\hline & Single crystal XRD\# & Au-S & 1.4 & 2.33 & & & & \\
\hline & & Au-Au (1) & 1.4 & 2.78 & & & & \\
\hline & & Au-Au (2) & 1.9 & 2.95 & & & & \\
\hline & & $\mathrm{Au}-\mathrm{Au}(3)$ & 2.9 & 3.16 & & & & \\
\hline \multirow[t]{7}{*}{38,24} & EXAFS at $8 \mathrm{~K}$ & Au-S & $1.2(2)$ & $2.315(4)$ & $0.0030(10)$ & 10.7 & $0.0012(5)$ & $416(57)$ \\
\hline & & $A u-A u(S)$ & $2.8(4)$ & $2.788(1)$ & $0.0041(4)$ & & $0.0028(12)$ & $153(11)$ \\
\hline & & Au-Au (L) & $1.6(9)$ & $2.982(15)$ & $0.0090(49)$ & & $0.0066(5)$ & $106(15)$ \\
\hline & Single crystal XRD ${ }^{\star *}$ & Au-S & 1.3 & 2.33 & & & & \\
\hline & & $\mathrm{Au}-\mathrm{Au}(1)$ & 2.7 & 2.82 & & & & \\
\hline & & $\mathrm{Au}-\mathrm{Au}(2)$ & 1.8 & 2.98 & & & & \\
\hline & & $\mathrm{Au}-\mathrm{Au}(3)$ & 2.2 & 3.21 & & & & \\
\hline \multirow[t]{7}{*}{144,60} & EXAFS at $8 \mathrm{~K}$ & Au-S & $0.9(2)$ & $2.326(8)$ & 0.0048 (29) & 12.7 & 0.0024 (9) & $381(45)$ \\
\hline & & $\mathrm{Au}-\mathrm{Au}(\mathrm{S})$ & $1.2(5)$ & $2.733(9)$ & $0.0035(20)$ & & $0.0021(5)$ & $148(11)$ \\
\hline & & $\mathrm{Au}-\mathrm{Au}(\mathrm{L})$ & $6.0(7)$ & $2.870(4)$ & $0.0059(13)$ & & $0.0041(6)$ & $128(9)$ \\
\hline & $\mathrm{DFT}^{\dagger \dagger}$ & Au-S & 0.8 & 2.34 & & & & \\
\hline & & $\mathrm{Au}-\mathrm{Au}(1)$ & 1.5 & 2.77 & & & & \\
\hline & & $\mathrm{Au}-\mathrm{Au}(2)$ & 5.9 & 2.92 & & & & \\
\hline & & Au-Au (3) & 1.5 & 3.24 & & & & \\
\hline \multicolumn{9}{|c|}{ 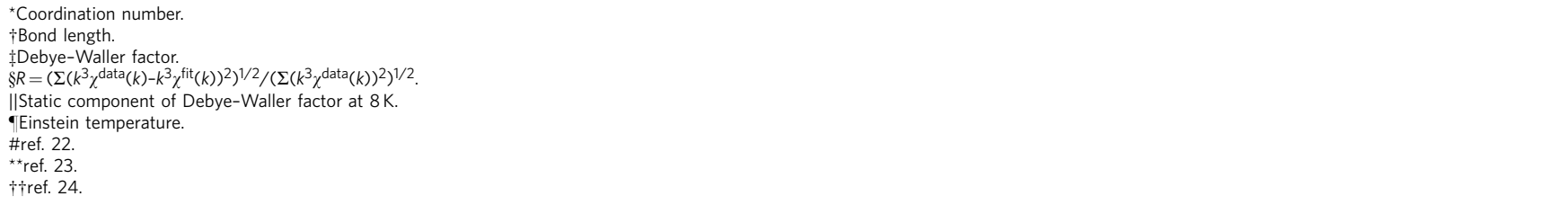 } \\
\hline
\end{tabular}


$\mathrm{Au}-\mathrm{Au}(2)$ bonds, respectively. The FT-EXAFS spectrum simulated using DW factors for each of the Au sites shown in Supplementary Fig. 3 reproduced the experimental spectrum (Supplementary Fig. 5).

These analyses demonstrate that low-temperature EXAFS data provides quantitative structural information on the $\mathrm{Au}$ bonds within the $\mathrm{Au}$ cores of $\mathrm{Au}_{n}(\mathrm{SR})_{m}$. Following this successful characterization, we next conducted $\mathrm{Au} \mathrm{L}_{3}$-edge EXAFS measurement of $\mathrm{Au}_{144}(\mathrm{PET})_{60}$ at $8 \mathrm{~K}$, of which the structure has not yet been determined by single-crystal XRD. Au $\mathrm{L}_{3}$-edge EXAFS oscillation was clearly observed in the $k$ range as large as $21.0 \AA^{-1}$, as shown in Fig. 2a. The FT-EXAFS spectrum of $\mathrm{Au}_{144}(\mathrm{PET})_{60}$ (Fig. 2b) shows a small peak for the $\mathrm{Au}-\mathrm{S}$ bond in the range of $1.5-2.0 \AA$ and a large peak for the $\mathrm{Au}-\mathrm{Au}$ bond in the range of 2.1-3.0 $\AA$. The curve-fitting analysis indicates that the data can be reproduced by assuming Au-S $(\mathrm{CN}=0.9$, $r=2.326 \AA), \mathrm{Au}-\mathrm{Au}(\mathrm{S})(\mathrm{CN}=1.2, r=2.733 \AA)$ and $\mathrm{Au}-\mathrm{Au}(\mathrm{L})$ $(\mathrm{CN}=6.0, r=2.870 \AA$ ) bonds, as shown in Table 1. The $\mathrm{Au}-\mathrm{Au}$ bonds are slightly shorter than those of $\mathrm{Au}_{25}(\mathrm{PET})_{18}$ and $\mathrm{Au}_{38}(\mathrm{PET})_{24}$, whereas the $\mathrm{Au}-\mathrm{S}$ bond length is comparable to those of $\mathrm{Au}_{25}(\mathrm{PET})_{18}$ and $\mathrm{Au}_{38}(\mathrm{PET})_{24}$. According to density functional theory (DFT) calculations ${ }^{24}, \mathrm{Au}_{144}\left(\mathrm{SCH}_{3}\right)_{60}$ has a hollow icosahedral $\mathrm{Au}_{12}$ core. The absence of the central $\mathrm{Au}$ atom may be a cause of the reduction in the $\mathrm{Au}-\mathrm{Au}$ bond lengths compared with those of $\mathrm{Au}_{25}(\mathrm{PET})_{18}$ and $\mathrm{Au}_{38}(\mathrm{PET})_{24}$. Supplementary Figure 1c plots the bond lengths between the nearest neighbour $\mathrm{Au}$ atoms in $\mathrm{Au}_{144}\left(\mathrm{SCH}_{3}\right)_{60}$ obtained by DFT calculations ${ }^{24}$. When $\mathrm{Au}-\mathrm{Au}$ bonds are divided into three groups $\mathrm{Au}-\mathrm{Au}(x)(x=1-3)$ with border distances of 2.83 and $3.10 \AA$, the experimentally obtained $\mathrm{CN}$ and $r$ values of the $\mathrm{Au}-\mathrm{S}, \mathrm{Au}-\mathrm{Au}(\mathrm{S})$ and $\mathrm{Au}-\mathrm{Au}(\mathrm{L})$ bonds are in quantitative agreement with those of the $\mathrm{Au}-\mathrm{S}, \mathrm{Au}-\mathrm{Au}(1)$ and $\mathrm{Au}-\mathrm{Au}(2)$ bonds, respectively, as shown in Table 1. The EXAFS analysis strongly supports the $\mathrm{Au}_{144}\left(\mathrm{SCH}_{3}\right)_{60}$ model structure ${ }^{24}$. We then examined which $\mathrm{Au}-\mathrm{Au}$ bonds contribute mainly to the $\mathrm{Au}-\mathrm{Au}(1)$ and $\mathrm{Au}-\mathrm{Au}(2)$ bonds. When the $\mathrm{Au}$ atoms of $\mathrm{Au}_{144}\left(\mathrm{SCH}_{3}\right)_{60}$ are divided into three groups: $12 \mathrm{Au}$ atoms at the hollow icosahedral core $\left(\mathrm{Au}_{\mathrm{C}}\right), 102 \mathrm{Au}$ atoms located at the middle and the outermost layers $\left(\mathrm{Au}_{\mathrm{S}}\right)$ and $30 \mathrm{Au}$ atoms at the oligomer $\left(\mathrm{Au}_{\mathrm{O}}\right)$ (Fig. 1), the $\mathrm{Au}-\mathrm{Au}(1)$ and $\mathrm{Au}-\mathrm{Au}(2)$ bonds are assigned mainly to the $A u_{C}-A_{C}$ and $A u_{S}-A_{S}$ bonds, respectively. The EXAFS oscillation is again dominated by the $\mathrm{Au}-\mathrm{Au}$ bonds in the core and the shell, whereas the contribution from the bonds with $\mathrm{Au}_{\mathrm{O}}$ is negligibly small. The FT-EXAFS spectrum simulated using DW factors for each of the $\mathrm{Au}$ sites shown in Supplementary Fig. 3 corresponded well with the experimental spectrum (Supplementary Fig. 6).

Einstein temperatures for $\mathbf{A u}-\mathbf{S}$ and $\mathbf{A u}-\mathbf{A u}$ bonds. The $\mathrm{DW}$ factors for the $\mathrm{Au}-\mathrm{S}, \mathrm{Au}-\mathrm{Au}(\mathrm{L})$ and $\mathrm{Au}-\mathrm{Au}(\mathrm{S})$ bonds of $\mathrm{Au}_{n}(\mathrm{PET})_{m}(n=25,38,144)$ were determined by least-squares fit analysis while keeping the $\mathrm{CN}$ values the same as those in Table 1, and the results are plotted as a function of temperature in Fig. 3. Details of the analysis are given in Methods section. Figure 3 shows that the DW factors for both the $\mathrm{Au}-\mathrm{Au}(\mathrm{S})$ and $\mathrm{Au}-\mathrm{Au}(\mathrm{L})$ bonds increase monotonically with the temperature, whereas those of $\mathrm{Au}-\mathrm{S}$ bonds remain almost constant in the temperature range of $8-300 \mathrm{~K}$ in all clusters. The $\mathrm{DW}$ factors for the $\mathrm{Au}-\mathrm{Au}(\mathrm{S})$ bonds are smaller than those for the $\mathrm{Au}-\mathrm{Au}(\mathrm{L})$ bonds and are comparable to that for the $\mathrm{Au}-\mathrm{Au}$ bond in the bulk $\mathrm{Au}$ (Supplementary Fig. 7).

The stiffnesses of the $\mathrm{Au}-\mathrm{S}$ bonds and two types of $\mathrm{Au}-\mathrm{Au}$ bonds of $\mathrm{Au}_{n}(\mathrm{PET})_{m}(n=25,38,144)$ were evaluated within the framework of the Einstein model. In the framework of the Einstein model, we assume three independent quantum oscillators with different Einstein frequencies $\left(\omega_{\mathrm{E}}\right)$ for the $\mathrm{Au}-\mathrm{S}$, $\mathrm{Au}-\mathrm{Au}(\mathrm{L})$ and $\mathrm{Au}-\mathrm{Au}(\mathrm{S})$ bonds. The Einstein temperatures $\left(\theta_{\mathrm{E}}\right)$ were determined by fitting the temperature dependence of the $\mathrm{DW}$ factors for the $\mathrm{Au}-\mathrm{S}, \mathrm{Au}-\mathrm{Au}(\mathrm{L})$ and $\mathrm{Au}-\mathrm{Au}(\mathrm{S})$ bonds. Details of the fitting procedure are given in Methods section. The best-fit results are shown in Fig. 3, and the optimized $\theta_{\mathrm{E}}$ and $\sigma_{\mathrm{S}}^{2}$ values are listed in Table 1.

\section{Discussion}

In this study, the hierarchy of the bond stiffnesses within $\mathrm{Au}_{n}(\mathrm{PET})_{m}(n=25,38,144)$ was examined using $\mathrm{Au} \mathrm{L} \mathrm{L}_{3}$-edge EXAFS. EXAFS results provided quantitative structural information ( $r$ and $\mathrm{CN}$ values) of two types of $\mathrm{Au}-\mathrm{Au}$ bonds $(\mathrm{Au}-\mathrm{Au}(\mathrm{S})$ and $\mathrm{Au}-\mathrm{Au}(\mathrm{L}))$ within the Ih-based $\mathrm{Au}$ cores in addition to the $\mathrm{Au}-\mathrm{S}$ bonds. The temperature dependence of the DW factors of the individual bonds was analysed within the framework of the Einstein model. Einstein temperatures for the two types of $\mathrm{Au}-\mathrm{Au}$ bonds were determined to be much lower than that of the $\mathrm{Au}-\mathrm{S}$ bonds in all clusters, which suggests that thiolate-protected $\mathrm{Au}$ clusters can be viewed as soft Au cores capped by rigid Au-SR staples. This is in agreement with the results of molecular dynamic (MD) simulation on a model system $\mathrm{Au}_{25}(\mathrm{SH})_{18}^{-}$that the $-\mathrm{SR}-(\mathrm{Au}-\mathrm{SR})_{2}-$ units are rigid and confine the elastic Au core internally ${ }^{28}$.
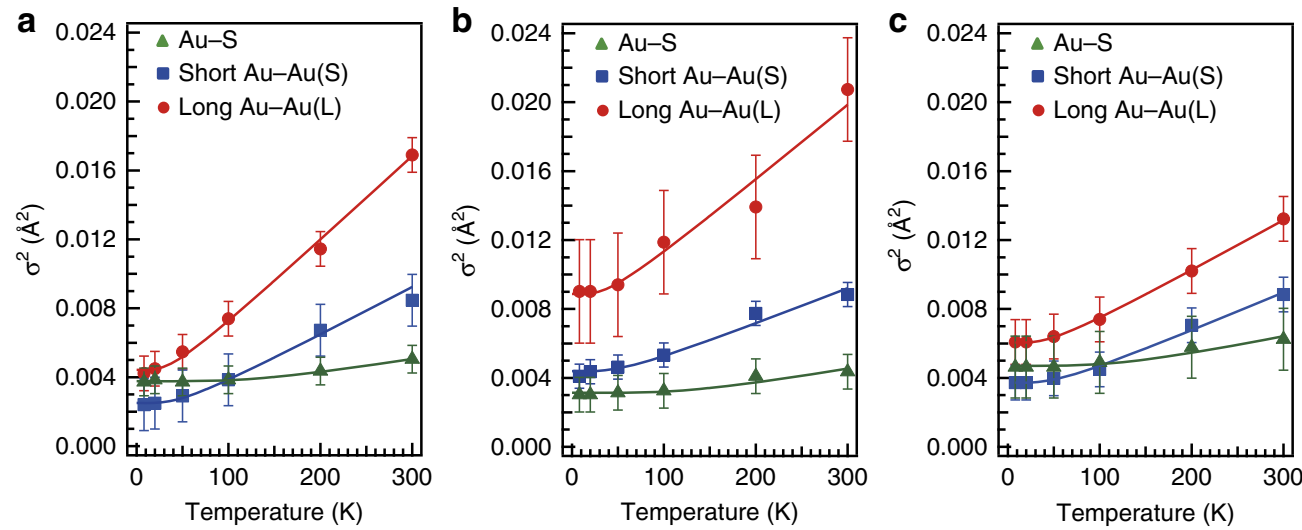

Figure 3 | Temperature dependence of the DW factors. Temperature dependence of the DW factors $\left(\sigma^{2}\right)$ for $A u-S, A u-A u(S)$ and $A u-A u(L)$ bonds. (a) $\mathrm{Au}_{25}(\mathrm{PET})_{18}$ (b) $\mathrm{Au}_{38}(\mathrm{PET})_{24}$ and (c) $\mathrm{Au}_{144}(\mathrm{PET})_{60}$. Solid lines represent the fitting results. Error bars represent the s.d. in the curve-fitting procedure of FT-EXAFS. 

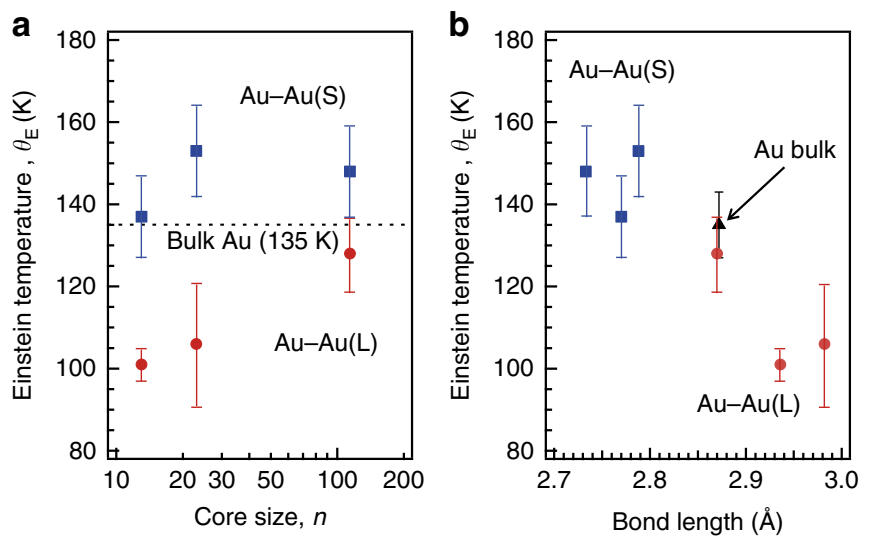

Figure 4 | Einstein temperature. (a) Einstein temperature $\left(\theta_{\mathrm{E}}\right)$ as a function of the core size and (b) bond length for $\mathrm{Au}-\mathrm{Au}(\mathrm{S})$ (square) and $\mathrm{Au}-\mathrm{Au}(\mathrm{L})$ (circle) bonds for core size of $n=13,23$ and 114. $\theta_{\mathrm{E}}$ and $\mathrm{Au}-\mathrm{Au}$ bond distance for bulk $A u$ are $135 \mathrm{~K}$ and $2.872 \AA$, respectively. Error bars represent the s.d. in the fitting procedure of $\theta_{\mathrm{E}}$.

More interestingly, two classes of $\mathrm{Au}-\mathrm{Au}$ bonds with different stiffnesses were identified. Figure $4 \mathrm{a}$ shows the Einstein temperatures of the $\mathrm{Au}-\mathrm{Au}(\mathrm{S})$ and $\mathrm{Au}-\mathrm{Au}(\mathrm{L})$ bonds as a function of the $\mathrm{Au}$ core sizes $(13,23,114)$ of $\mathrm{Au}_{n}(\mathrm{PET})_{m}$ and that of $\mathrm{Au}-\mathrm{Au}$ bonds in the bulk $\mathrm{Au}(135 \pm 8 \mathrm{~K})^{29}$. This plot indicates that the $\mathrm{Au}-\mathrm{Au}(\mathrm{S})$ and $\mathrm{Au}-\mathrm{Au}(\mathrm{L})$ bonds are respectively stiffer and more flexible than the $\mathrm{Au}-\mathrm{Au}$ bonds in the face-centred cubic bulk $\mathrm{Au}$, regardless of the cluster size. To the best of our knowledge, this result is the first experimental verification of hierarchy of $\mathrm{Au}-\mathrm{Au}$ bond stiffnesses in thiolateprotected $\mathrm{Au}$ clusters. The correlation suggests that the bond stiffness is related to the bond length. To confirm this hypothesis, Einstein temperatures of the $\mathrm{Au}-\mathrm{Au}$ bonds were plotted as a function of their lengths in Fig. $4 \mathrm{~b}$. The $\mathrm{Au}-\mathrm{Au}$ bond becomes stiffer with a reduction of the bond length. The $\mathrm{Au}-\mathrm{Au}(\mathrm{S})$ bonds that are shorter and stiffer than $\mathrm{Au}-\mathrm{Au}$ bonds in the bulk $\mathrm{Au}$ are specific to the Ih core because $\mathrm{Au}-\mathrm{Au}(\mathrm{S})$ bonds are formed along the radial direction in the icosahedral $\mathrm{Au}$ core. The formation of $\mathrm{Au}-\mathrm{Au}$ bonds in $\mathrm{Au}_{n}(\mathrm{PET})_{m}$ that are stiffer than those in the bulk $\mathrm{Au}$ is consistent with the theoretical prediction that the vibrational density of states distribution of the Ih cluster has a tail towards a higher frequency than that of bulk $\mathrm{Au}^{4,7,8}$. The $\mathrm{Au}-\mathrm{Au}(\mathrm{L})$ bonds between the surface $\mathrm{Au}$ atoms are more flexible on average than those in the bulk $\mathrm{Au}$, even though they are bonded with the rigid $\mathrm{Au}-\mathrm{SR}$ oligomers. The above consideration suggests that the Au core of the thiolate-protected Au clusters tends to deform more easily along the lateral direction than in the radial direction. This is consistent with theoretical prediction based on the MD simulation of $\mathrm{Au}_{25}(\mathrm{SH})_{18}^{-}$that $\mathrm{Au}$ core atoms prefer vibrating in the tangential directions as opposed to the radial direction ${ }^{28}$.

Close inspection of the distribution of $\mathrm{Au}-\mathrm{Au}(\mathrm{S})$ bonds reveals that the stiff $\mathrm{Au}-\mathrm{Au}$ bonds are distributed not only in the centre of the core, but also on the surface of the core. For example, $6 \mathrm{Au}_{\mathrm{S}}-\mathrm{Au}_{\mathrm{S}}$ bonds and $12 \mathrm{Au}_{\mathrm{C}}-\mathrm{Au}_{\mathrm{S}}$ bonds in $\mathrm{Au}_{25}(\mathrm{PET})_{18}$ are categorized as the $\mathrm{Au}-\mathrm{Au}(\mathrm{S})$ bonds, as shown in Fig. 5a. By bridging these stiff $\mathrm{Au}-\mathrm{Au}$ surface bonds with the $-\mathrm{SR}-(\mathrm{Au}-$ $\mathrm{SR})_{2}$ - oligomers, a ring structure is formed in $\mathrm{Au}_{25}(\mathrm{PET})_{18}$ (Fig. 5b). Similar ring structures can be found in $\mathrm{Au}_{38}(\mathrm{PET})_{24}$ and $\mathrm{Au}_{144}(\mathrm{PET})_{60}$ (Fig. $\left.5 \mathrm{c}, \mathrm{d}\right)$. Tlahuice-Flores et al..$^{30}$ also suggested the formation of circular networks $\left(\mathrm{Au}_{20} \mathrm{Cl}_{10}\right)$ with short $\mathrm{Au}-\mathrm{Au}$ and $\mathrm{Au}-\mathrm{Cl}$ bonds as subunits in $\mathrm{Au}_{144} \mathrm{Cl}_{60}^{2+}$, which is modelled by replacement of the SR ligands of $\mathrm{Au}_{144}(\mathrm{SR})_{60}$ with $\mathrm{Cl}$. These results suggest that thiolate-protected Au clusters contain rigid a
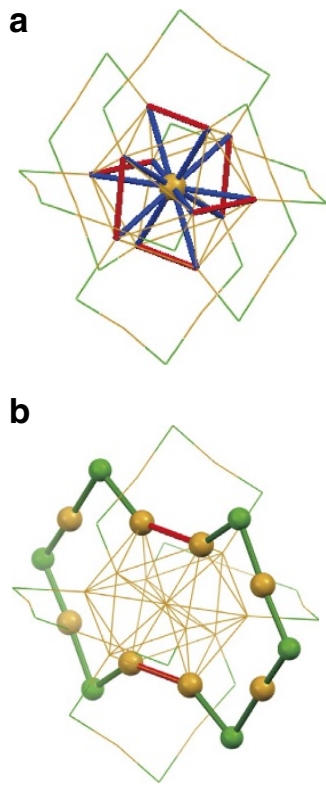

C

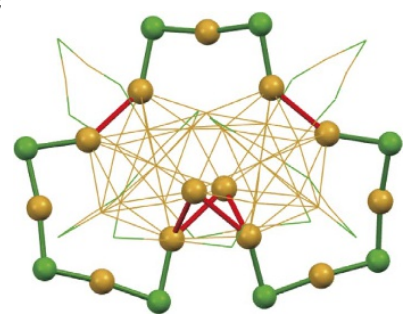

d

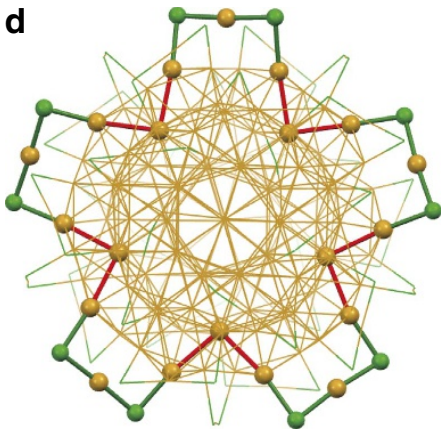

Figure 5 | Network structures of stiff bonds. (a) Distribution of stiff $\mathrm{Au}-\mathrm{Au}$ bonds in $\mathrm{Au}_{25}(\mathrm{PET})_{18}$. Red and blue bonds represent $\mathrm{Au}_{\mathrm{s}}-\mathrm{Au}_{\mathrm{s}}$ and $\mathrm{Au}_{\mathrm{C}}-\mathrm{Au}_{\mathrm{S}}$ bonds, respectively. Ring structures in (b) $\mathrm{Au}_{25}(\mathrm{PET})_{18}$, (c) $\mathrm{Au}_{38}(\mathrm{PET})_{24}$ and (d) $\mathrm{Au}_{144}(\mathrm{PET})_{60}$.

ring subunits that consist of short $\mathrm{Au}-\mathrm{Au}$ bonds at the surface and $\mathrm{Au}-\mathrm{SR}$ staples. The formation of these rigid ring structures may act as frameworks to enhance the thermal stability of the thiolate-protected Au clusters.

\section{Methods}

Chemicals. Hydrogen tetrachloroaurate tetrahydrate $\left(\mathrm{HAuCl}_{4} \cdot 4 \mathrm{H}_{2} \mathrm{O}\right)$ was purchased from Tanaka Kikinzoku. phenylethanethiol, tetraoctylammonium bromide $(\mathrm{TOABr})$, sodium tetrahydroborate $\left(\mathrm{NaBH}_{4}\right)$, methanol, acetone, dichloromethane and toluene were obtained from Wako Pure Chemical Industries. All chemicals were used without further purification. Deionized water with a resistivity above $18.2 \mathrm{M} \Omega \mathrm{cm}$ was used.

Synthesis and characterization. $\mathrm{Au}_{25}(\mathrm{PET})_{18}$ was synthesized by the methods similar to that in the literature ${ }^{31}$. First, $\mathrm{HAuCl}_{4} \cdot 4 \mathrm{H}_{2} \mathrm{O}(0.75 \mathrm{mmol})$ was dissolved in $25 \mathrm{ml}$ tetrahydrofuran solution containing $\mathrm{TOABr}(0.76 \mathrm{mmol})$ at room temperature. After stirring for $15 \mathrm{~min}$, phenylethanethiol $(4.7 \mathrm{mmol})$ was added to this solution and the solution was stirred for $15 \mathrm{~min}$. A cold aqueous solution $(5.8 \mathrm{ml})$ containing $\mathrm{NaBH}_{4}(8.7 \mathrm{mmol})$ was then rapidly added to the solution and then the solution was stirred at room temperature. After $12 \mathrm{~h}$, tetrahydrofuran solvent was evaporated and the remaining red brown powder was washed with methanol to remove excess thiol and other byproducts. The $\mathrm{Au}_{25}(\mathrm{PET})_{18}$ cluster was extracted from the dried sample using acetonitrile.

$\mathrm{Au}_{38}(\mathrm{PET})_{24}$ was synthesized by the methods similar to that in the literature ${ }^{32}$. First, $\mathrm{HAuCl}_{4} \cdot 4 \mathrm{H}_{2} \mathrm{O}(0.50 \mathrm{mmol})$ and glutathione $(0.25 \mathrm{mmol})$ were dissolved in acetone $(20 \mathrm{ml})$. This solution was stirred for $15 \mathrm{~min}$ at room temperature and for another $15 \mathrm{~min}$ at $0{ }^{\circ} \mathrm{C}$. A cold aqueous solution $(6.0 \mathrm{ml})$ containing $\mathrm{NaBH}_{4}$ $(5.0 \mathrm{mmol})$ was then rapidly added to this solution and the solution was stirred in ice bath. After $15 \mathrm{~min}$, the acetone was discarded and the residue was dissolved in water $(6.0 \mathrm{ml})$. This solution was then added to the mixture of toluene $(2.0 \mathrm{ml})$ and ethanol $(0.30 \mathrm{ml})$ containing phenylethanethiol $(15 \mathrm{mmol})$. The resulting solution was stirred at $80^{\circ} \mathrm{C}$. After $12 \mathrm{~h}$, the organic solution was evaporated and the resulting black powder was washed by methanol to remove byproducts. The $\mathrm{Au}_{38}(\mathrm{PET})_{24}$ thus obtained was further purified by the gel permeation chromatography.

$\mathrm{Au}_{144}(\mathrm{PET})_{60}$ was synthesized by the methods similar to that in the literature ${ }^{33}$ First, $\mathrm{HAuCl}_{4} \cdot 4 \mathrm{H}_{2} \mathrm{O}(0.60 \mathrm{mmol})$ and $\mathrm{TOABr}(0.69 \mathrm{mmol})$ were dissolved in methanol $(30 \mathrm{ml})$ at room temperature. After stirring for $5 \mathrm{~min}$, phenylethanethiol ( $3.7 \mathrm{mmol})$ was added to this solution and the solution was stirred for $15 \mathrm{~min}$. A cold aqueous solution $(10 \mathrm{ml})$ containing $\mathrm{NaBH}_{4}(6.0 \mathrm{mmol})$ was then rapidly added to this solution and the solution was stirred at room temperature. After $4 \mathrm{~h}$, the black precipitate was separated by centrifugation and washed repeatedly with methanol or acetonitrile to remove excess thiol, byproducts and the other-sized 
clusters. The $\mathrm{Au}_{144}(\mathrm{PET})_{60}$ thus obtained was further purified by gel permeation chromatography.

Chemical compositions and purities of the $\mathrm{Au}_{n}(\mathrm{PET})_{m}$ samples were confirmed by a high-resolution Fourier-transform mass spectrometer with an electrospray ionization source (Bruker, Solarix). A $1-\mathrm{mg} \mathrm{ml}^{-1}$ dispersion of $\mathrm{Au}_{n}(\mathrm{SR})_{m}$ in toluene/acetonitrile $(1: 1, \mathrm{v}-\mathrm{v})$ was electrosprayed at a flow rate of $800 \mu \mathrm{l}$ per hour. Ultraviolet-visible-near infrared (UV-Vis-NIR) spectra of $\mathrm{Au}_{n}(\mathrm{PET})_{m}$ in toluene were recorded with a spectrometer (Jasco, V-670).

EXAFS measurements. Au $\mathrm{L}_{3}$-edge EXAFS measurements were conducted using the BL01B1 beamline at the SPring-8 facility of the Japan Synchrotron Radiation Research Institute. The incident X-ray beam was monochromatized by a $\mathrm{Si}(311)$ double crystal monochromator. A solid sample of each $\mathrm{Au}_{n}(\mathrm{PET})_{m}$ cluster was diluted with boron nitride powder, pressed into a pellet, and then mounted on a copper holder attached to a cryostat. All EXAFS spectra were measured in the transmission mode using ionization chambers at $8-300 \mathrm{~K}$. The X-ray energy was calibrated using $\mathrm{Cu}$ foil. The EXAFS analysis was conducted using REX2000 Ver. 2.5.9 program (Rigaku Co.) as follows. The $\chi$ spectra were extracted by subtracting the atomic absorption background using cubic spline interpolation and were normalized to the edge height. The $k^{3}$-weighted $\chi$ spectra within the $k$ ranges of $3.0-21.0 \AA^{-1}$ for structural analysis and of $3.0-16.0 \AA^{-1}$ for analysis of temperature dependence of the DW factor were Fourier-transformed into $r$ space. The curve-fitting analysis was performed for $\mathrm{Au}-\mathrm{S}$ and $\mathrm{Au}-\mathrm{Au}$ bonds over the $r$ range of $1.5-3.1 \AA$. In the curve-fitting analysis, the phase shifts and back-scattering amplitude functions for $\mathrm{Au}-\mathrm{S}$ and $\mathrm{Au}-\mathrm{Au}$ were extracted from $\mathrm{Au}_{2} \mathrm{~S}$ (ICSD\#78718) and Au metal (ICSD\#44362), respectively, using the FEFF8 program ${ }^{34}$ by setting $\sigma^{2}$ to 0.0036 . This $\sigma^{2}$ value did not significantly affect the phase shift and back-scattering amplitude functions. EXAFS spectra for $\mathrm{Au}_{n}(\mathrm{PET})_{m}$ were also simulated using the FEFF8 (ref. 34) programs. Reported crystal structures for $\mathrm{Au}_{25}(\mathrm{PET})_{18}$ (ref. 22) and $\mathrm{Au}_{38}(\mathrm{PET})_{24}$ (ref. 23) and the calculated structure for $\mathrm{Au}_{144}\left(\mathrm{SCH}_{3}\right)_{60}$ (ref. 24) were used for the EXAFS simulations. The theoretical bond lengths for the $\mathrm{Au}_{144}\left(\mathrm{SCH}_{3}\right)_{60}$ structure were scaled by 0.974 because the Perdew, Burke and Ernzerhof approximation used to the exchange-correlation functional overestimates the $\mathrm{Au}-\mathrm{Au}$ bond lengths ${ }^{24}$. Different $\mathrm{DW}$ factors for $\mathrm{Au}$ atoms at different sites, as shown in Supplementary Fig. 3, were used for EXAFS simulations because the DW factors for Au atoms are dependent on the sites shown in Table 1.

Evaluation of DW factors. The EXAFS equation is generally expressed as:

$$
\chi(k)=S_{0}^{2} \sum \frac{\mathrm{CN}}{k r^{2}} f(k ; \pi) \exp \left(-2 \sigma^{2} k^{2}\right) \sin \left(2 k r+\delta(k)-\frac{4}{3} C_{3} k^{3}\right),
$$

where $S_{0}^{2}, \mathrm{CN}, k, r, f(k ; \pi), \sigma^{2}, \delta(k)$ and $C_{3}$ are passive electron reduction factor, coordination number, photoelectron energy, bond distance, back-scattering amplitude function, DW factor, phase shift, and the third cumulant, respectively ${ }^{35}$. Supplementary Figure 9 shows FT-EXAFS spectra for $\mathrm{Au}_{n}(\mathrm{PET})_{m}$ at various temperatures obtained from the temperature-dependent EXAFS data $\left(3.0 \leq k \leq 16.0 \AA^{-1}\right)$ (Supplementary Fig. 8). It was confirmed by the analysis of bulk $\mathrm{Au}$ that the temperature dependence of $C_{3}$ must be taken into account in addition to the $\sigma^{2}$ and $r$ values (Supplementary Fig. 7) ${ }^{14}$ to reproduce the FT-EXAFS spectra. $C_{3}, r$ and $\sigma^{2}$ values for individual $\mathrm{Au}-\mathrm{S}$ and $\mathrm{Au}-\mathrm{Au}$ bonds were determined by least-squares fit analysis while keeping the $\mathrm{CN}$ values the same as those in Table 1, and the results are plotted as a function of temperature in Supplementary Fig. 10. In all clusters, the DW factors for both the $\mathrm{Au}-\mathrm{Au}(\mathrm{S})$ and $\mathrm{Au}-\mathrm{Au}(\mathrm{L})$ bonds increase monotonically with the temperature, whereas those of $\mathrm{Au}-\mathrm{S}$ bonds remain almost constant in the temperature range of $8-300 \mathrm{~K}$ (Supplementary Fig. 10). The DW factors for the $\mathrm{Au}-\mathrm{Au}(\mathrm{S})$ bonds are smaller than those for the $\mathrm{Au}-\mathrm{Au}(\mathrm{L})$ bonds and are comparable to that for the $\mathrm{Au}-\mathrm{Au}$ bond in the bulk Au (Supplementary Figs 7 and 10).

Evaluation of Einstein temperatures. The DW factor $\sigma^{2}$ is composed of a dynamic component $\sigma_{\mathrm{D}}^{2}$ and a static component $\sigma_{\mathrm{S}}^{2}$, which arises from the thermal atomic oscillation and the temperature-independent structural disorder, respectively:

$$
\sigma^{2}=\sigma_{\mathrm{S}}^{2}+\sigma_{\mathrm{D}}^{2}
$$

We assume within the framework of the Einstein model three independent quantum oscillators with different Einstein frequencies $\left(\omega_{\mathrm{E}}\right)$ for the Au-S and Au$\mathrm{Au}$ bonds. The Einstein temperature $\left(\theta_{\mathrm{E}}\right)$ is defined as:

$$
\theta_{\mathrm{E}}=\frac{h \omega_{\mathrm{E}}}{2 \pi k_{\mathrm{B}}},
$$

where $h$ and $k_{\mathrm{B}}$ are the Planck and Boltzmann constants, respectively. According to the Einstein model, the dynamic DW factor $\sigma_{\mathrm{D}}^{2}$ can be fitted using the equation:

$$
\sigma_{\mathrm{D}}^{2}=\frac{h^{2}}{8 \pi^{2} \mu k_{\mathrm{B}} \theta_{\mathrm{E}}} \operatorname{coth} \frac{\theta_{\mathrm{E}}}{2 T},
$$

where $\mu$ and $T$ represent the reduced mass of adjacent atoms and the temperature, respectively. The $\theta_{\mathrm{E}}$ values were determined by fitting the temperature dependence of the DW factors for the $\mathrm{Au}-\mathrm{S}, \mathrm{Au}-\mathrm{Au}(\mathrm{L})$ and $\mathrm{Au}-\mathrm{Au}(\mathrm{S})$ bonds using equations (2)-(4). The best-fit results are shown in Fig. 3, and the optimized $\theta_{\mathrm{E}}$ and $\sigma_{\mathrm{S}}^{2}$ values are listed in Table 1.

\section{References}

1. Bai, H. Y., Luo, J. L. \& Jin, D. Particle size and interfacial effect on the specific heat of nanocrystalline Fe. J. Appl. Phys. 79, 361-364 (1996)

2. Schmidt, M., Kusche, R., Issendorff, B. V. \& Haberland, H. Irregular variations in the melting point of size-selected atomic clusters. Nature 393, 238-240 (1998).

3. Narvaez, G. A., Kim, J. \& Wilkins, W. Effects of morphology on phonons of nanoscopic silver grains. Phys. Rev. B 72, 155411 (2005).

4. Araujo, L. L., Kluth, P., Azevedo, G. M. \& Ridgway, M. C. Vibrational properties of Ge nanocrystals determined by EXAFS. Phys. Rev. B 74, 184102 (2006).

5. Buffat, P. \& Borel, J.-P. Size effect on the melting temperature of gold particles. Phys. Rev. A 13, 2287-2298 (1976).

6. Cleveland, C. L., Luedtke, W. D. \& Landman, U. Melting of gold clusters: icosahedral precursors. Phys. Rev. Lett. 81, 2036-2039 (1998).

7. Sauceda, H. E., Salazar, F., Pérez, L. A. \& Garzón, I. L. Size and shape dependence of the vibrational spectrum and low-temperature specific heat of Au nanoparticles. J. Phys. Chem. C 117, 25160-25168 (2013).

8. Ortigoza, M. A., Heid, R., Bohnen, K.-P. \& Rahman, T. S. Anomalously soft and stiff modes of transition-metal nanoparticles. J. Phys. Chem. C 118, 10335-10347 (2014).

9. Yang, C. C., Xiao, M. X., Li, W. \& Jiang, Q. Size effects on Debye temperature, Einstein temperature, and volume thermal expansion coefficient of nanocrystals. Solid State Commun. 139, 148-152 (2006).

10. Cuenya, B. R. et al. Size-dependent evolution of the atomic vibrational density of states and thermodynamic properties of isolated Fe nanoparticles. Phys. Rev. B 86, 165406 (2012).

11. Yokoyama, T., Kimoto, S. \& Ohta, T. Temperature-dependent EXAFS study on supported silver and palladium clusters. Jpn J. Appl. Phys. 28, L851-L853 (1989).

12. Cuenya, B. R. et al. Thermodynamic properties of Pt nanoparticles: size, shape, support, and adsorbate effects. Phys. Rev. B 84, 245438 (2011).

13. Cuenya, B. R. et al. Anomalous lattice dynamics and thermal properties of supported size- and shape-selected Pt nanoparticles. Phys. Rev. B 82, 155450 (2010).

14. Comaschi, T., Balerna, A. \& Mobilio, S. Temperature dependence of the structural parameters of gold nanoparticles investigated with EXAFS. Phys. Rev. B 77, 075432 (2008).

15. Dubiel, M. et al. Temperature dependence of EXAFS cumulants of Ag nanoparticles in glass. J. Phys. Conf. Ser. 190, 012123 (2009).

16. Sauceda, H. E., Pelayo, J. J., Salazar, F., Pérez, L. A. \& Garzón, I. L. Vibrational spectrum, caloric curve, low-temperature het capacity, and Debye temperature of sodium clusters: the $\mathrm{Na}_{139}^{+}$case. J. Phys. Chem. C 117, 11393-11398 (2013).

17. Giovanetti, L. J. et al. Anomalous vibrational properties induced by surface effects in capped Pt nanoparticles. J. Phys. Chem. C 111, 7599-7604 (2009)

18. Kang, J. H., Menard, L. D., Nuzzo, R. G. \& Frenkel, A. I. Unusual non-bulk properties in nanoscale materials: thermal metal-metal bond contraction of $\gamma$-alumina-supported Pt catalysts. J. Am. Chem. Soc. 128, 12068-12069 (2006)

19. Sanchez, S. I. et al. The emergence of nonbulk properties in supported metal clusters: negative thermal expansion and atomic disorder in Pt nanoclusters supported on $\gamma-\mathrm{Al}_{2} \mathrm{O}_{3}$. J. Am. Chem. Soc. 131, 7040-7054 (2009).

20. Tsukuda, T. \& Häkkinen, H. Protected Metal Clusters: from Fundamentals to Applications (Elsevier, 2015).

21. Heaven, M. W., Dass, A., White, P. S., Holt, K. M. \& Murray, R. W. Crystal structure of the gold nanoparticle $\left[\mathrm{N}\left(\mathrm{C}_{8} \mathrm{H}_{17}\right)_{4}\right]\left[\mathrm{Au}_{25}\left(\mathrm{SCH}_{2} \mathrm{CH}_{2} \mathrm{Ph}\right)_{18}\right]$. J. Am. Chem. Soc. 130, 3754-3755 (2008).

22. Zhu, M., Aikens, C. M., Hollander, F. J., Schatz, G. C. \& Jin, R. Correlating the crystal structure of a thiol-protected $\mathrm{Au}_{25}$ cluster and optical properties. J. Am. Chem. Soc. 130, 5883-5885 (2008).

23. Qian, H., Echenhoff, W. T., Zhu, Y., Pintauer, T. \& Jin, R. Total structure determination of thiolate-protected $\mathrm{Au}_{38}$ nanoparticles. J. Am. Chem. Soc. 132, 8280-8281 (2010).

24. Lopez-Acevedo, O., Akola, J., Whetten, R. L., Grönbeck, H. \& Häkkinen, H. Structure and bonding in the ubiquitous icosahedral metallic gold cluster $\mathrm{Au}_{144}(\mathrm{SR})_{60}$. J. Phys. Chem. C 113, 5035-5038 (2009).

25. Weissker, H.-Ch. et al. Information on quantum states pervades the visible spectrum of the ubiquitous $\mathrm{Au}_{144}(\mathrm{SR})_{60}$ gold nanocluster. Nat. Commun. 5, 3785 (2014).

26. Zhang, P. X-ray spectroscopy of gold-thiolate nanoclusters. J. Phys. Chem. C 118, 25291-25299 (2014).

27. Chevrier, D. M., Yang, R., Chatt, A. \& Zhang, P. Bonding properties of thiolateprotected gold nanoclusters and structural analogs from X-ray absorption spectroscopy. Nanotechnol. Rev. 4, 193-206 (2015). 
28. Mäkinen, V. \& Häkkinen, H. Density functional theory molecular dynamics study of the $\mathrm{Au}_{25}(\mathrm{SH})_{18}^{-}$cluster. Eur. Phys. J. D 66, 310 (2011).

29. Kluth, P. et al. Vibrational properties of Au and Cu nanocrystals formed by ion implantation. AIP Conf. Proc. 882, 731-733 (2007).

30. Tlahuice-Flores, A., Black, D. M., Bach, S. B. H., Yose-Yacamán, M. \& Whetten, R. L. Structure \& bonding of the gold-subhalide cluster $I-\mathrm{Au}_{144} \mathrm{Cl}_{60}^{[z]}$. Phys. Chem. Chem. Phys. 15, 19191-19195 (2013).

31. Dharmaratne, A. C., Krick, T. \& Dass, A. Nanocluster size evolution studied by mass spectrometry in room temperature $\mathrm{Au}_{25}(\mathrm{SR})_{18}$ synthesis. J. Am. Chem. Soc. 131, 13604-13605 (2009).

32. Qian, H., Zhu, Y. \& Jin, R. Size-focusing synthesis, optical and electrochemical properties of monodisperse $\mathrm{Au}_{38}\left(\mathrm{SC}_{2} \mathrm{H}_{4} \mathrm{Ph}\right)_{24}$ nanoclusters. ACS Nano 3 , 3795-3803 (2009).

33. Qian, H. \& Jin, R. Ambient synthesis of $\mathrm{Au}_{144}(\mathrm{SR})_{60}$ nanoclusters in methanol. Chem. Mater. 23, 2209-2217 (2011).

34. Ankudinov, A. L., Ravel, B., Rehr, J. J. \& Conradson, S. D. Real-space multiplescattering calculation and interpretation of X-ray-absorption near-edge structure. Phys. Rev. B 58, 7565-7576 (1998).

35. Tranquada, J. M. \& Ingalls, R. Extended X-ray-absorption fine-structure study of anharmonicity in CuBr. Phys. Rev. B 28, 3520-3528 (1983).

\section{Acknowledgements}

The EXAFS measurements were conducted under an approval of JASRI (Proposal Nos 2015A1590, 2014B1430, 2013B1659, 2013B1421, 2012B1421 and 2012B1986). We thank Professor Hannu Häkkinen (University of Jyväskylä) for providing atomic coordinates of $\mathrm{Au}_{144}\left(\mathrm{SCH}_{3}\right)_{60}$ obtained by DFT calculations. This research was financially supported by the Funding Program for Next Generation World-leading Researchers (NEXT Program, GR-003), 'Elements Strategy Initiative to Form Core Research Center', a Grant-in-Aid for Scientific Research (No. 26248003) from the MEXT (Ministry of Education, Culture,
Sports, Science and Technology) and a Grant for Basic Science Research Projects from The Sumitomo Foundation.

\section{Author contributions}

S.Y. and T.T. designed this study. Y.N. and W.K. synthesized and characterized the gold cluster samples. K.N. developed a sample holder for low-temperature XAFS measurements. S.Y. and S.T. conducted the XAFS measurements. S.Y. analysed the experimental and theoretical spectra with the help of T.Y. All authors took part in the writing of this manuscript.

\section{Additional information}

Supplementary Information accompanies this paper at http://www.nature.com/ naturecommunications

Competing financial interests: The authors declare no competing financial interests.

Reprints and permission information is available online at http://npg.nature.com/ reprintsandpermissions/

How to cite this article: Yamazoe, S. et al. Hierarchy of bond stiffnesses within icosahedral-based gold clusters protected by thiolates. Nat. Commun. 7:10414 doi: $10.1038 /$ ncomms10414 (2016).

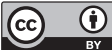

This work is licensed under a Creative Commons Attribution 4.0 International License. The images or other third party material in this article are included in the article's Creative Commons license, unless indicated otherwise in the credit line; if the material is not included under the Creative Commons license, users will need to obtain permission from the license holder to reproduce the material. To view a copy of this license, visit http://creativecommons.org/licenses/by/4.0/ 